\title{
Electrochemical Rutile and Anatase formation on PEO surfaces
}

\author{
A. E. R. Friedemann ${ }^{a b c^{*}}$, Th. M. Gesing ${ }^{\text {bc }}$, P. Plagemann ${ }^{a}$
}

${ }^{a}$ FRAUNHOFER Institut für Fertigungstechnik Angewandte Materialforschung IFAM, Wiener Straße 12, D-28359 Bremen, Germany

${ }^{\mathrm{b}}$ Institut für Anorganische Chemie und Kristallographie, Leobener Straße /NW2, Bibliothekstraße 1, Universität Bremen, D-28359 Bremen, Germany

${ }^{c}$ MAPEX Center for Materials and Processes, Bibliothekstraße 1, Universität Bremen, D-28359 Bremen, Germany

* Corresponding author. Tel.: +49 421 2246-7365;

E-mail address: ariane.friedemann@ifam.fraunhofer.de (A. E. R. Friedemann).

\begin{abstract}
A highly porous surface with a high crystalline content and resultant photocatalytic activity is ensured through the process of plasma electrolytic oxidation on pure titanium. In the present study the morphology, crystallinity and photocatalytic activity of plasma electrolytic oxidized $\mathrm{TiO}_{2}$-surfaces were investigated. The surfaces were prepared in acidic and alkaline electrolytes over an applied voltage range between $50 \mathrm{~V}$ and $300 \mathrm{~V}$ to optimize the crystalline and photocatalytic properties. Scanning electron microscopy (SEM) and X-ray powder diffraction (XRD) were selected to determine the morphologies which differ according to the type of electrolyte as well as the crystal structures of anatase and rutile on the surface material, which increase with the applied voltage. The oxide surfaces did not show morphological differences compared to typical PEO surfaces with the exception of oxide films obtained in $\mathrm{H}_{2} \mathrm{SO}_{4}$-solution which also exhibited an astounding amount of rutile even with low applied voltages. The increased parts of anatase and rutile on the surfaces resulted in photocatalytic activity, which was investigated under UV-light using methylene blue, while the PEO surfaces showed degradation activity. There is an indication that a high proportion of anatase and small amounts of rutile in the PEO layers positively influence photocatalytic activity.
\end{abstract}

Keywords: Plasma electrolytic oxidation, $\mathrm{TiO}_{2}$ layer, Anatase, Rutile, Crystallinity, Photocatalytic activity 


\section{Introduction}

Since the middle of the last century, the use of titanium has permitted many innovative applications [1-4]. Plasma electrolytic oxidation (PEO) (also known as: micro arc oxidation MAO, plasma chemical oxidation and anodic spark deposition) is a type of high-voltage anodic oxidation capable of producing a stable oxide layer with a wide range of coating structures on lightweight metals ( $\mathrm{Al}, \mathrm{Zr}, \mathrm{Mg}$, Ti, etc.). This technic was first mentioned in 1880 by Sluginov et al. [5] and further developed in 1937 by Schulze and Betz [6]. Since the 1960s, PEO has been used for the formation of oxide layers on different metals [7-10]. Plasma electrolytic oxidation is very suitable as a surface treatment because it enables the combined adjustment of both the morphology and chemical composition, while offering the possibility of generating a uniform crystalline surface in a single step [11]. The process includes chemical, electrochemical and thermodynamical reactions where by the local temperature increases by $10^{3}$ and $10^{4} \mathrm{~K}$ due to the plasma micro-discharges [12] which are the reason for the formation of a partly crystalline surface. PEO allows high levels of layer thickness and surface roughness in contrast to other chemical metal surface treatments, which increase linearly with regard to the applied voltage.

In several publications the effects of different mixtures of electrolytes on the morphology of $\mathrm{TiO}_{2}$ coatings have been described [13-15]. It is possible to obtain a typical porous- and crater-like structure with solutions containing different mixtures of acids [16] and other morphological distributions can be achieved by changing the electrolytic compounds and such process parameters as the applied voltage. The photocatalytic activity of $\mathrm{TiO}_{2}$ on crystalline PEO surfaces has been reported by different authors [14,17-20]. However, the effects of the electrolytic system on crystallinity as well as the associated photocatalytic activity of the PEO surfaces have until now not been thoroughly investigated. These PEO coatings also possess a high porosity and an associated large specific surface for the absorption of photons [21,22]. Often, however, only small crystalline phase contents are achieved in these coatings, which has a strong influence on the photochemical properties [22-26]. In this study, plasma electrolytic oxidized titania layers were investigated with regards to their morphology and crystalline surfaces. The photocatalytic behaviors of the crystalline surfaces were examined using the degradation of methylene blue (MB), a typical organic dye. 


\section{Materials and experimental details}

2.1 Preparation of titanium test plates for PEO treatment

The samples used for the oxidation process were cut from a bar of pure titanium (grade 1) into rectangular plates of the dimension of $1.5 \mathrm{~cm} \times 1 \mathrm{~cm}$. The plates were cleaned with a solution of SurTec $₫ 152$ for 10 min and etched with Turco $₫ 5578$ for 5 min to remove the natural oxide layer and to create a uniform surface. The chemicals used are listed in Tab. 1. After rinsing with pure water for 3 min the plates were oxidized in the chosen electrolytes (Tab. 2).

Tab. 1: Used chemicals in the present study

\begin{tabular}{lll}
\hline Chemical & Purity & Manufacturer \\
\hline SurTec®152 & $<5 \%$ Fatalcoholethoxalate & Sur Tec (Bernsheim, Germany) \\
& $20 \% \mathrm{Na}_{2} \mathrm{CO}_{3}$ & \\
& $<5 \%$ Coconutoilaminoxethylat & \\
Turco®5578 & $10-30 \% \mathrm{NaOH}$ & Henkel (Düsseldorf, Germany) \\
& $1-10 \%$ Triethanolamine & \\
& $1-10 \%$ Sodiumgluconate & \\
Sulfuric acid $\mathrm{H}_{2} \mathrm{SO}_{4}$ & $95-97 \%$ & AppliChem (Darmstadt, Germany) \\
Phosphoric acid $\mathrm{H}_{3} \mathrm{PO}_{4}$ & $85 \%$ & AppliChem (Darmstadt, Germany) \\
Calciumacetate $\mathrm{Ca}_{2}\left(\mathrm{C}_{2} \mathrm{H}_{3} \mathrm{O}_{2}\right)_{2}$ & $\geq 99 \%$ & Sigma Aldrich Co. LL (Steinheim, Germany) \\
Sodium- $\beta$-Glycerophosphate $\mathrm{NaC}_{3} \mathrm{H}_{7} \mathrm{O}_{6} \mathrm{P}$ & $\approx 99.9 \%$ & Sigma Aldrich Co. LL (Steinheim, Germany) \\
& $\leq 0.1 \%$ inorganic phosphorus & \\
\hline Sodium tartrate $\mathrm{C}_{4} \mathrm{H}_{4} \mathrm{Na}_{2} \mathrm{O}_{6}$ & $\leq 1.0$ mol\% L- $\alpha$-isomer & \\
Sodium hydroxide $\mathrm{NaOH}$ & $\geq 99 \%$ & Sigma Aldrich Co. LL (Steinheim, Germany) \\
\hline
\end{tabular}

Tab. 2: Chemical contents of the used electrolytes

\begin{tabular}{lll}
\hline Parameter & Concentration/ Components & Discharge voltages/ V \\
\hline Electrolyte 1 & $0.3 \mathrm{M} \mathrm{H}_{3} \mathrm{PO}_{4}, 1.5 \mathrm{M} \mathrm{H}_{2} \mathrm{SO}_{4}$ & $100-280$ \\
Electrolyte 2 & $0.2 \mathrm{M} \mathrm{Ca}_{\left(\mathrm{C}_{2} \mathrm{H}_{3} \mathrm{O}_{2}\right)_{2}, 0.02 \mathrm{M} \mathrm{NaC}_{3} \mathrm{H}_{7} \mathrm{O}_{6} \mathrm{P}}$ & $180-320$ \\
Electrolyte 3 & $1.5 \mathrm{M} \mathrm{H}_{2} \mathrm{SO}_{4}$ & $80-220$ \\
Electrolyte 4 & $1.5 \mathrm{M} \mathrm{H}_{3} \mathrm{PO}_{4}$ & $180-320$ \\
Electrolyte 5 & $0.5 \mathrm{M} \mathrm{NaOH} 0.2 \mathrm{M} \mathrm{Na}-$ Tartrate & $50-140$ \\
\hline
\end{tabular}




\subsection{Plasma electrolytic oxidation process}

The $\mathrm{TiO}_{2}$ layers were produced in five different aqueous electrolytes as listed in Tab. 2. The mixed acid electrolyte should generate a clear surface morphology that is also most regular. These two acids were chosen in order to compare the difference in the surfaces produces by both the mixture and the pure acidic electrolytes. The electrolyte containing the calcium compound should form a biocompatible surface and the second alkaline electrolyte has a composition that should smooth the PEO surfaces. A typical experimental setup for performing the PEO process is presented schematically in Fig. 1. The oxidation process of the pretreated samples was carried out in an ice-cooled glass beaker. The experiments were performed with a two electrode circuit whereby a titanium plate was used as the permanent counter electrode and the titanium sample was the working electrode. Both electrodes were placed in the electrolyte and contacted with a metal clip. A commercially available power supply EA PS $836015 \mathrm{~T}$ (0 - 360 V, 0 - 15 A, 1500 W, EA Elektro-Automatik GmbH \& Co. KG Viersen, Germany) was used. The voltage ramp from 0 to a maximum of $300 \mathrm{~V}$ and the holding time was set using the software UTA 12 (Fraunhofer IFAM). For all samples a polarization time of $15 \mathrm{~min}$ was applied after a ramp time of $3 \mathrm{~min}$ to reach the maximum voltage. The resolution of the current measurement was nominally $0.01 \mathrm{~A}$. During the polarization process the temperature increased with increasing voltage. Therefore, the whole electrolyte solution was cooled by ice circulation and hold between $290 \mathrm{~K}$ and $303 \mathrm{~K}$. During the whole process the solution was stirred on a digital magnetic stirrer (IKA-Werke GmbH \& Co. KG, Staufen, Germany) and the current flow and breakdown voltages were continuously recorded. Finally the samples were rinsed in demineralized water and air dried at room temperature.

a)

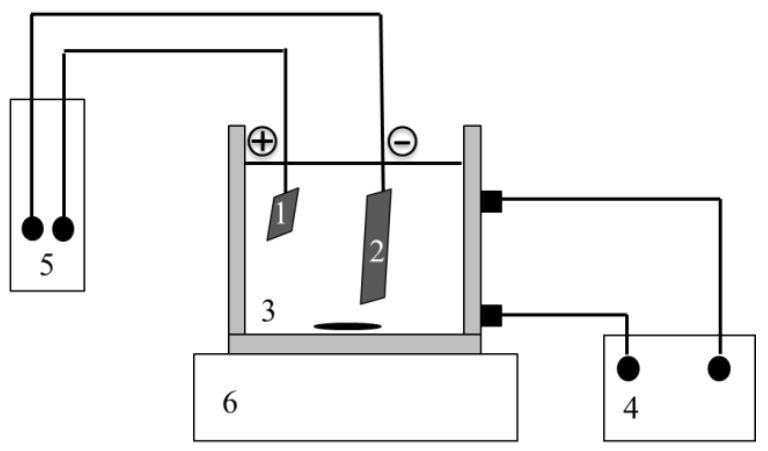

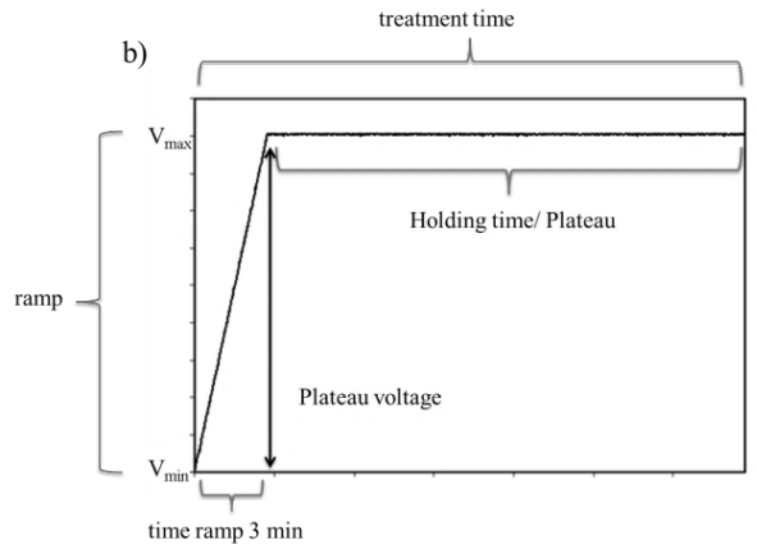

Fig. 1: a) Experimental setup for plasma electrolytic oxidation with anode oxidized titanium (1), cathode titanium plate (2), electrolyte (3), pump with ice water cooling (4), power supply (5) and a stirring bar (6); b) scheme of experimental treatment during the PEO process 


\subsection{Structural analysis}

The examination of the crystallinity of the oxidized titanium surfaces was performed by X-ray diffraction analysis. Data were collected on a Xpert MPD powder diffractometer (PANalytical, Kassel, Germany) with Ni-filtered $\mathrm{Cu}-\mathrm{K} \alpha_{1,2}$-radiation $\left(\lambda_{\alpha 1}=1.540596 \mathrm{~nm}, \lambda_{\alpha 2}\right.$ $=1.544493 \mathrm{~nm}$ ) in Bragg-Brentano geometry. Measurements were carried out from $20^{\circ}$ to $100^{\circ} 2 \theta$ with a step-size of $0.0167^{\circ}$ per 3 seconds. To investigate the microstructure of the prepared PEO surfaces scanning electron microscopy (SEM) was used. These investigations were carried out in a FEI Helios 600 Dual-Beam (Oregon, USA) field emission scanning electron microscope (FESEM). For focused ion beam (FIB) analysis the samples were covered with a thin platinum layer to ensure conductivity for secondary and backscattering electrons. During the focused ion beam measurements the samples were tilted at an angle of $52^{\circ}$ to obtain the coating thickness. This angle was factored into the measurement of the thickness from the used program. An Everhart-Thornley or an InLense-Detector was used for imaging.

\subsection{Photocatalytic test}

The photocatalytic activity was measured by observing the degradation of methylene blue (MB, AppliChem GmbH, Darmstadt, Germany) in an aqueous solution. Using a Cary ${ }^{\circledR} 50$ Conc UV/Vis-spectrometer (Varian Inc., Agilent Technologies, Santa Clara, USA). The degradation was measured over a period of four days detecting the change of the methylene blue after UV-illumination. Changes were analyzed based on the Lambert-Beer equation (I: Intensity of transmitted light, $\mathrm{I}_{0}$ : Intensity of irradiated light, c: concentration, $\varepsilon$ : extinction coefficient, d: layer thickness).

$E=\lg \left(\frac{I_{0}}{I}\right)=\varepsilon \cdot c \cdot d$

During the test the PEO titanium plates produced $(1.5 \mathrm{x} 1 \mathrm{~cm})$ were immersed into $3 \mathrm{~mL}$ of the prepared $37 \mathrm{mM}$ methylene blue solution and irradiated with a $25 \mathrm{~W}$ UV-lamp (blacklight, Phillips, Germany). Data were collected for each after one day of irradiation. To exclude the desorption effects of MB, a pure MB sample was irradiated during the test and one PEO-treated sample was left in the dark, to exclude adsorption effects. Because methylene blue has an adsorption peak at $664 \mathrm{~nm}$ [18] the spectral region from $450 \mathrm{~nm}$ to 800 $\mathrm{nm}$ was taken to analyze the degradation by comparing the respective adsorption intensity of this mode. 


\section{Results and discussion}

\subsection{Plasma electrolytic oxidation measurement}

During the electrochemical process, a high amount of characteristic micro-discharges occurred on the surface of the anode. These discharges are due to a local breakdown of the growing oxide layer which forms a porous- and "crater-like" structure [16,18]. During the treatment the current flow was controlled by in-situ current recording with a plugged power supply. Fig. 2 shows the characteristic breakdown voltages of each electrolytic system. It is well known that the electrolytic systems have a different effect on the breakdown voltage. Venkateswarlu et al. [27] ascribed a dependency of the breakdown voltage to the electrolyte conductivity and Ikonopisov et al. [28] developed an equation to show the linearity between breakdown voltage and the conductivity of the electrolytic system.

$V_{b}=a_{B}+b_{B} \cdot \log \frac{1}{\kappa}$

Where $\mathrm{V}_{\mathrm{b}}$ is the breakdown voltage, $\mathrm{a}_{\mathrm{B}}$ and $\mathrm{b}_{\mathrm{B}}$ are constant values for the electrolyte composition and $\kappa$ is the electrolyte conductivity. It is obvious that if the conductivity $\kappa$ decreases the value for $\mathrm{V}_{\mathrm{b}}$ increases.

There is a higher breakdown voltage for the alkaline electrolyte E2 (see Tab. 2) in contrast to the case of the acidic electrolytes E1 and E3, with the exception of electrolyte E4. The breakdown voltage decreases with an increase in the conductivity of the electrolyte (Tab. 2). In Fig. 2 a low breakdown voltage can be seen for electrolyte E1 and E3. Both electrolytes contain sulfuric acid,producing a high conductivity. E5 consists of an organic compound (tartaric acid) which has, according to Venkateswarlu et al. [27], a higher conductivity than the phosphoric acid used in E4. The $\mathrm{H}_{3} \mathrm{PO}_{4}$ electrolyte shows a high breakdown voltage similar to E2, which also contains phosphates.

Tab. 3: Conductivities of the used electrolytic systems at room temperature

\begin{tabular}{llllll}
\hline Electrolyte & E1 & E2 & E3 & E4 & E5 \\
\hline Conductivity $\mathbf{\kappa} / \mathbf{m S} \cdot \mathbf{c m}^{-1}$ & $631^{1}$ & $16.81^{2}$ & $611^{1}$ & $40.4^{2}$ & $101.9^{2}$ \\
\hline${ }^{1}$ CRC Handbook of Chemistry and Physics, W. M. Haynes, $96^{\text {th }}$ Edition, 2015-2016 \\
${ }^{2}$ WTW Cond 315i/ SET, Weilheim, Germany
\end{tabular}



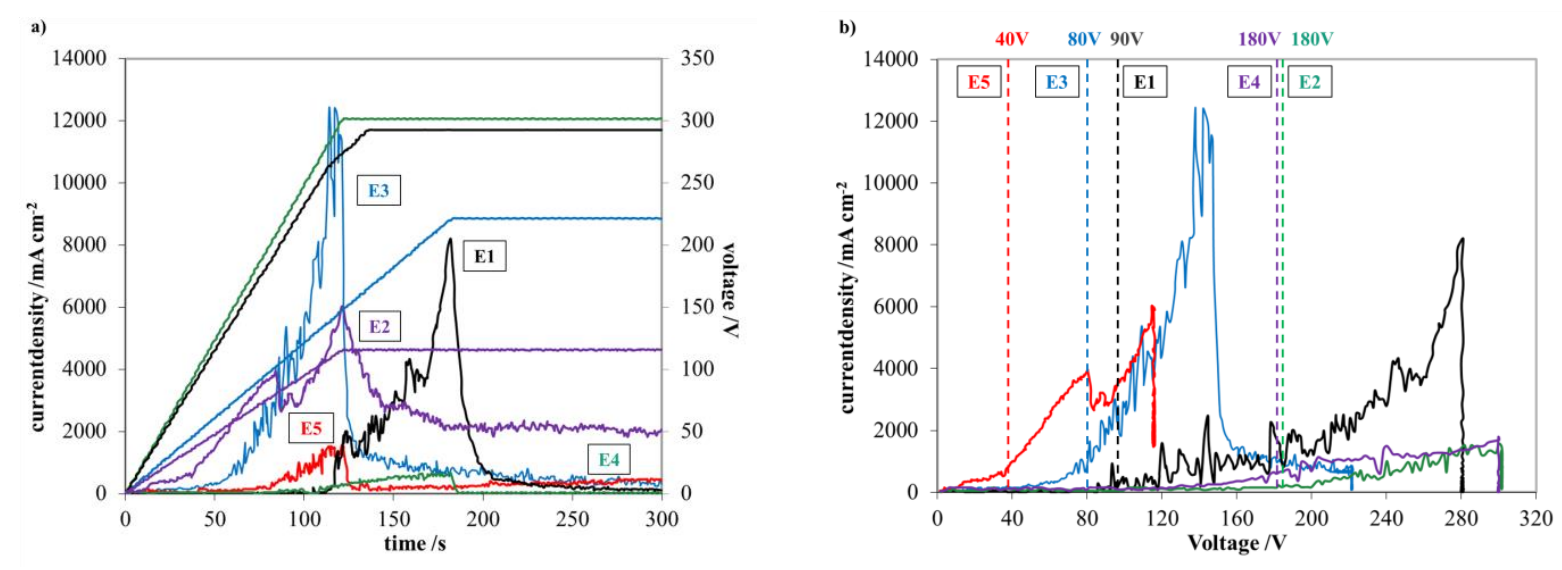

Fig. 2: a) Increasing current density during the PEO-process with the subside after the reaching of breakdown voltage b) Current density of the different electrolytic systems with the characteristically breakdown voltage where the PEO process starts

Su et al. [29] observe a lower oxidation ability in alkaline electrolytes because of the higher gas evolution at the anode. The balance of the oxide layer growing and the dissolution of the metal is more dependent on the solution rate of the metal in the electrolyte. This leads to a higher breakdown voltage for spark discharges. In contrast, the acidic electrolyte E4 has the same breakdown voltage as the alkaline electrolyte E2. This is related to the phosphate anion content. Kern et al. [30] describe an inhibitor relationship of phosphoric acid to the plasma electrolytic discharges during the process. This is similar to E2, which also contains phosphate components. Phosphate-containing electrolytes are less oxidizing, which increases the breakdown voltage. Furthermore, phosphoric acid promotes metal passivation and thus inhibits the discharges on the surface [31]. The alkaline electrolyte E5 shows an extremely low breakdown voltage of $40 \mathrm{~V}$. Su et al. [32] discovered a correlation between surface crystallinity and the oxidative behavior of the electrolyte. More aggressive contents improve the crystalline parts of the layers. Therefore it is possible to decrease the breakdown voltage with more oxidizing electrolytes, as also seen in Fig. 2 for E1 and E3 containing sulfuric acid. Yerokhin et al. [29] showed that $\mathrm{H}_{2} \mathrm{SO}_{4}$ provides a slow rate of metal dissolution, which causes a fast increase in current density during a small voltage range.

\subsection{Surface morphologies}

The titanium dioxide surfaces produced via plasma electrolytic oxidation in different electrolytes with the lowest and the highest applied treatment voltage is shown in Fig. 3. A surface morphology with typical porous and rough circular or elliptical pore shapes was formed on the basis of the occurrence of the micro-discharges previously reported. The left column of Fig. 3 shows the resulting surface morphology using the lowest voltage for the 
PEO process for each electrolytic system. At low voltages many little pores appear on the surfaces. With higher applied voltages (right side in Fig. 3), emerging larger pores are observed on the whole surface. The breakdown voltages of the PEO process had a significant effect onto the morphology of the surfaces. With increasing voltage the size of the pores increases too. This effect depends mostly on the increase of the applied voltage on the system. During the process the layer thickness grows continuously which happens along with a characteristic volume discharge forming sparks on the whole surface. The increase in the layer thickness with higher applied voltage can be seen in Fig. 4. The spark discharges between the oxide layer and the electrode are further enhanced by a significantly sharp rise in the current flow up to the end value. After reaching the end value the current decreases to a low constant current flow and, for the most parts, the oxide layer growth stops. With increasing anode potential a growing anodic oxide layer impedes the electron flow between the electrodes. With a definite thickness of the layer, the discharge and melting of the oxide cause a local breakdown in the layer. The layer growth is kinetically slowed because of the diffusion of $\mathrm{H}_{2} \mathrm{O}$ and $\mathrm{O}_{2}$ towards the bulk metal. Furthermore, defects on the surface lead to local breakdowns and form the characteristic pores on the PEO surfaces [19,33]. Ishizawa et al. [34], Bayati et al. [19] as well as Ito et al. [35] described a correlation of the applied voltage to the morphology and thickness of the PEO layer.

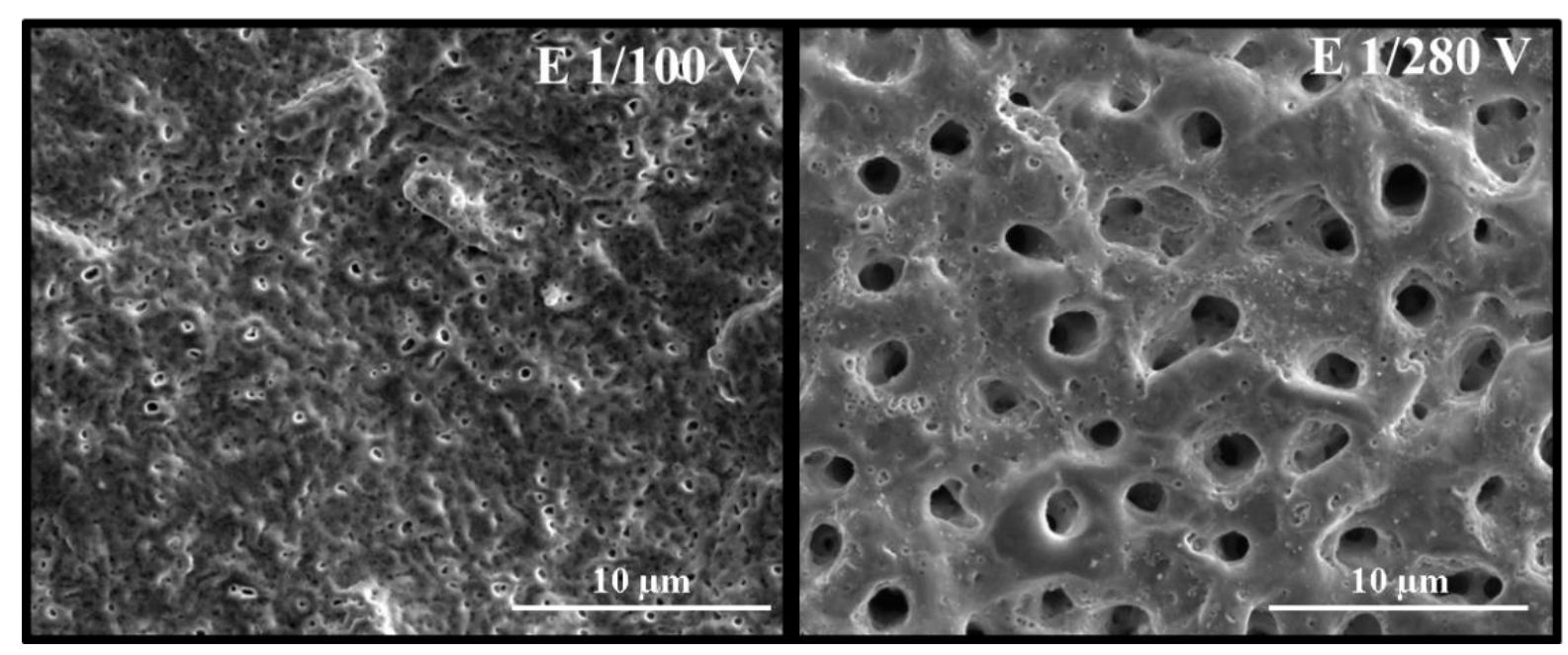



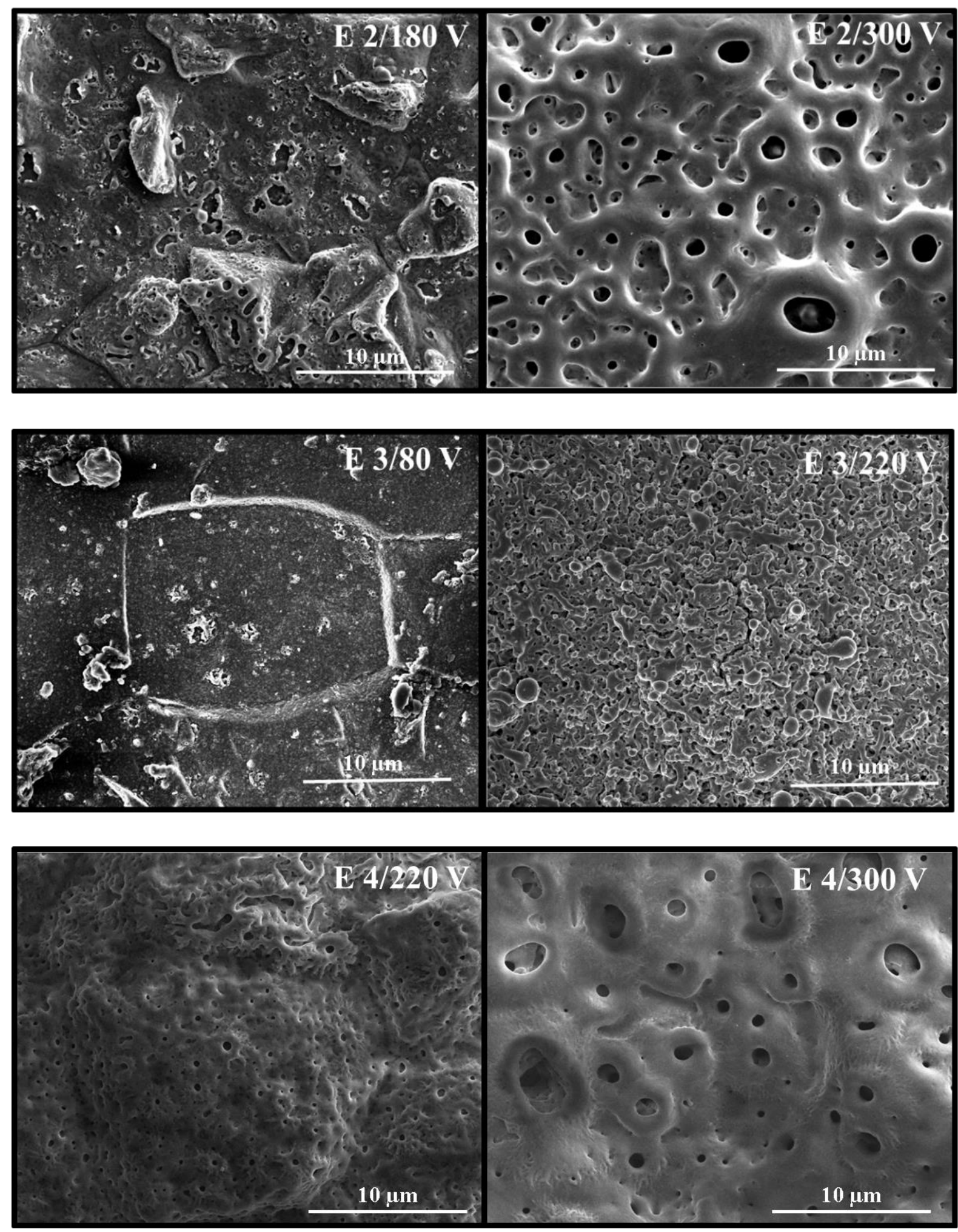


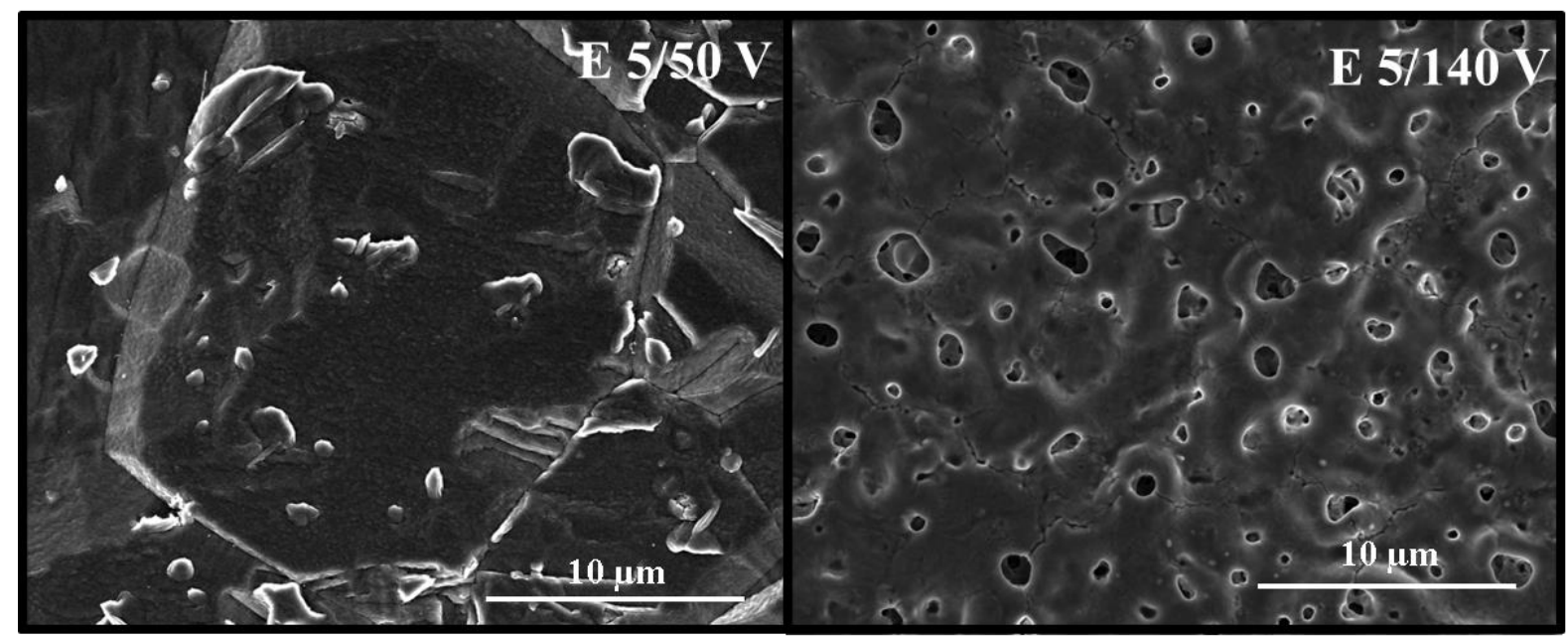

Fig. 3: SEM micrographs showing the surface topographies of the PEO treated Ti-plates in the different electrolytes (E1 E5).
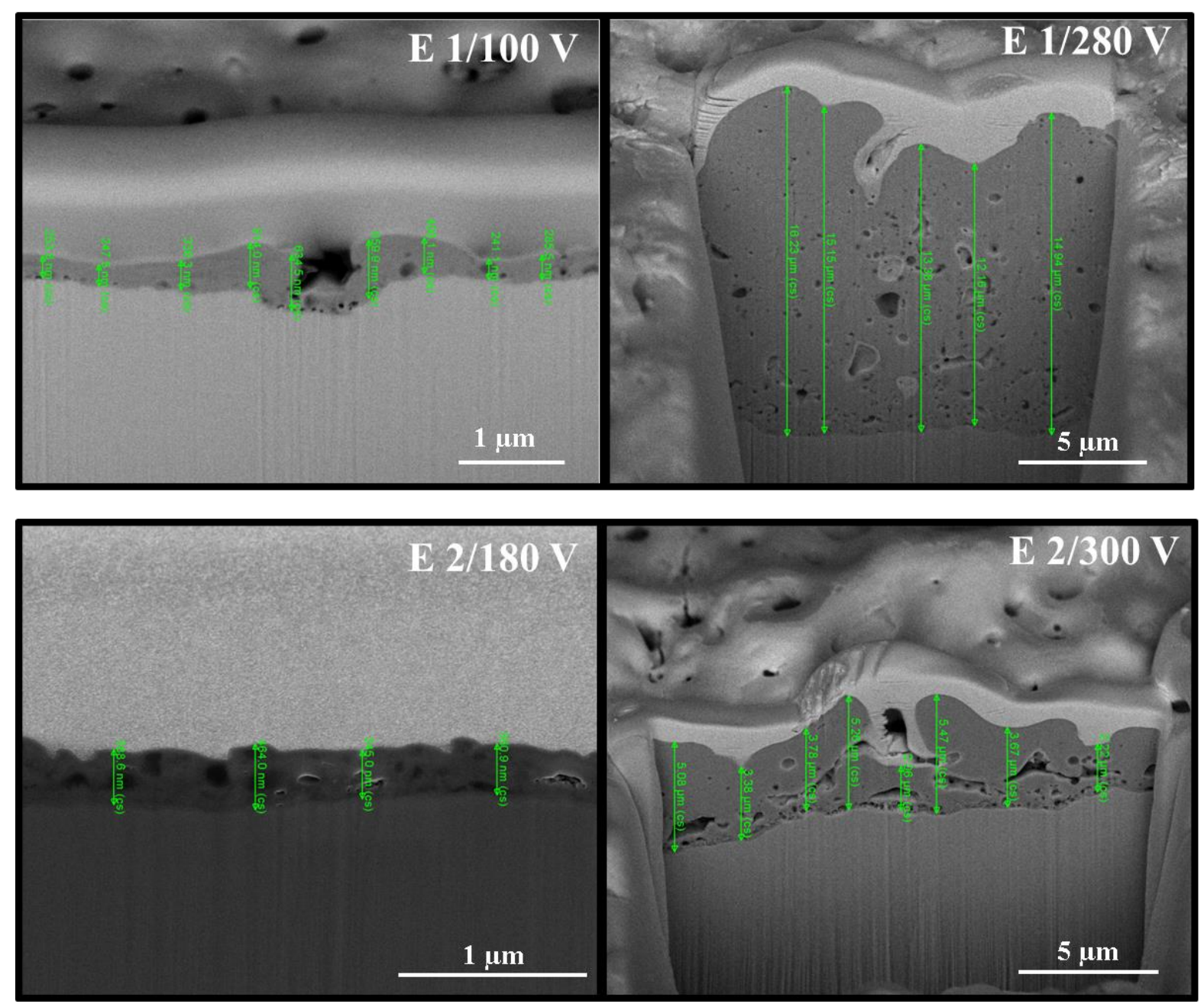

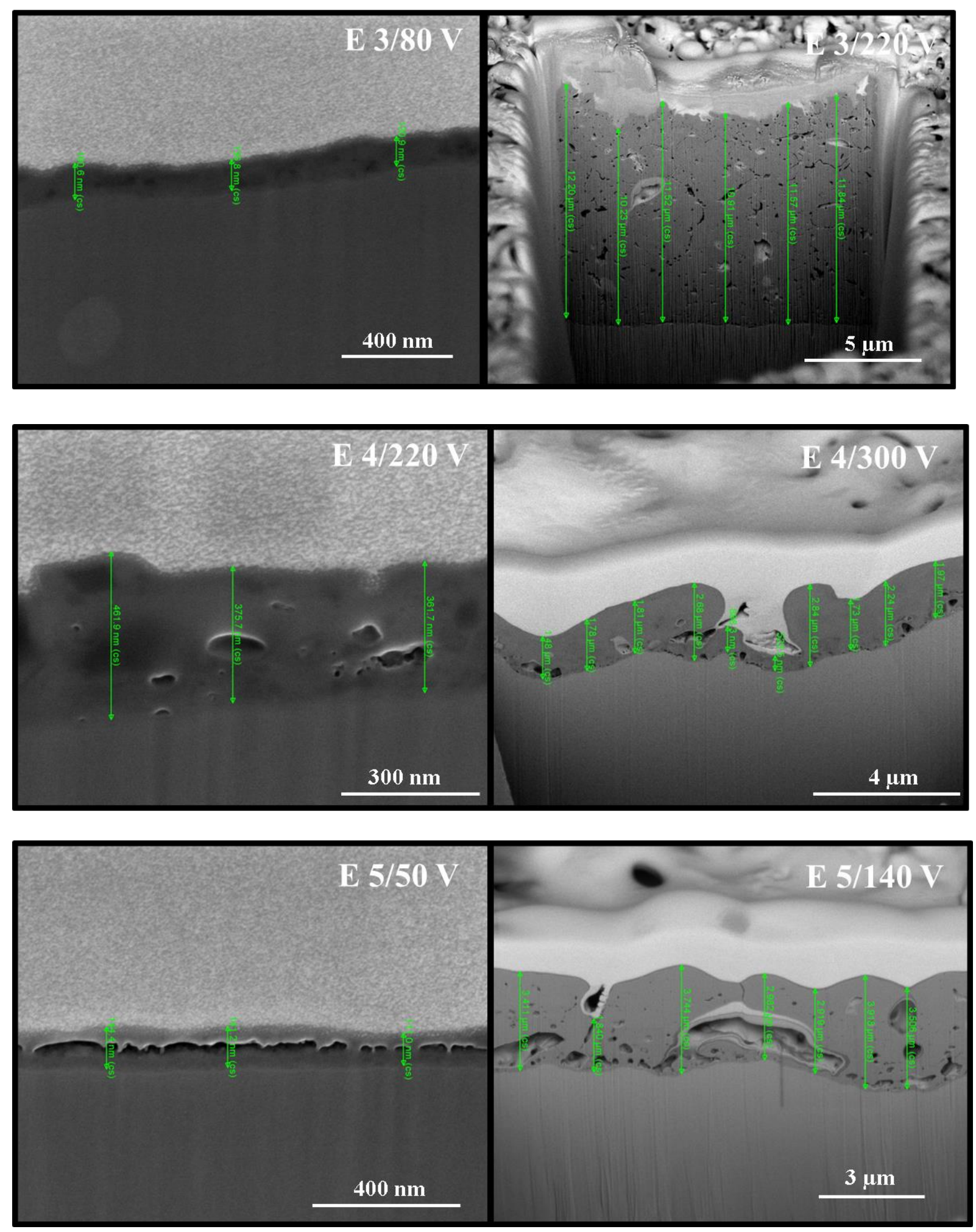

Fig. 4: SEM micrographs showing the oxide layer thickness of the PEO treated Ti-plates in the different electrolytes (E1 E5).

Using the different electrolytes, a change in the appearance of the surfaces can be observed. Nevertheless, all have a rough and porous structure. The surfaces using E1, E2 and E4 are quite similar. All surfaces have the typical "crater-like" pore shapes. The pores are relatively big, have bell mouths and are isolated from each other. In contrast to 
Venkateswarlu et al. [27], the pores of the phosphate $\left(\mathrm{PO}_{4}{ }^{2-}\right)$-containing electrolytes E1, E2 and E4 have a round shape compared to E3 and E5, which show a linear, flower-like structure with a connection of the pores inside the network. Furthermore, a round, isolated pore shape of the surfaces treated in borate $\left(\mathrm{B}_{4} \mathrm{O}_{7}{ }^{2-}\right)$ and silicate $\left(\mathrm{SiO}_{3}{ }^{2-}\right)$-containing electrolytes has been described [27]. These anions are twofold negatively charged. Therefore, the shapes of the pores may be explained by the character of the corresponding molecular charge of the components used in the electrolytic system. The electrolytes E1, E2 and E4 contain twofold negatively charged anions, which can influence the type of micro-discharges and thus the shape of the pores. In comparison to previous reports $[13,16,18,36,37]$, the titanium surfaces treated in different $\mathrm{PO}_{4}{ }^{2-}$-containing electrolytes show a similar appearance and pore shape as the produced surfaces given in Fig. 3 for E1, E2, E4 and E5. For E5, the pores have the same shape as the other surfaces, but slightly smaller pores can be observed that are not as pronounced as in the other three electrolytes. This electrolyte contains $\mathrm{NaOH}$ and the organic compound tartaric acid $\left(\mathrm{C}_{4} \mathrm{H}_{4} \mathrm{O}_{6}{ }^{2-}\right)$. Venkateswarlu et al. [27] also used an organic electrolyte containing citric acid $\left(\mathrm{C}_{6} \mathrm{H}_{5} \mathrm{O}_{7}{ }^{3-}\right)$. These treated surfaces look similar to the surfaces treated in tartaric acid, with a lower number of pores and more flat parts between the pores. Organic components have a significant influence on the volcano or "crater-like" structure of the pores and support a more plane surface. Only with electrolyte E3 did the surface not show a typical PEO pore shape. This can be described as a stacking of oxide layers with some cavities between these layers which can behave like pores, comparable to results published by Oh et al. [16]. These authors described the same pore shape for a $1.5 \mathrm{M} \mathrm{H}_{2} \mathrm{SO}_{4}$ electrolyte with a stack- like structure of the pore layers.

Tab. 4: Pore sizes and oxide layer thickness of the PEO surfaces treated in the different composited electrolytes

\begin{tabular}{l|ll|ll|ll|lll|ll}
\hline Electrolyte & E1 & & E2 & & E3 & & E4 & & E5 \\
\hline Applied voltage/ V & $\mathbf{1 0 0}$ & $\mathbf{2 8 0}$ & $\mathbf{1 8 0}$ & $\mathbf{3 0 0}$ & $\mathbf{8 0}$ & $\mathbf{2 2 0}$ & $\mathbf{2 2 0}$ & $\mathbf{3 0 0}$ & $\mathbf{5 0}$ & $\mathbf{1 4 0}$ \\
Pore size/ $\mu \mathrm{m}$ & 0.43 & 2.99 & 0.77 & 1.91 & - & 0.96 & 0.51 & 1.12 & - & 1.27 \\
& \pm 0.02 & \pm 0.5 & \pm 0.16 & \pm 0.7 & & \pm 0.05 & \pm 0.05 & \pm 0.21 & \pm 0.6 & \\
Oxide layer & 0.4 & 14.15 & 0.37 & 3.86 & 0.14 & 11.38 & 0.39 & 1.79 & 1.32 & 3.19 \\
thickness/ $\mu \mathrm{m}$ & \pm 0.17 & \pm 1.2 & \pm 0.14 & \pm 1.32 & \pm 0.01 & \pm 0.64 & \pm 0.06 & \pm 0.72 & \pm 0.13 & \pm 0.65 \\
\hline
\end{tabular}



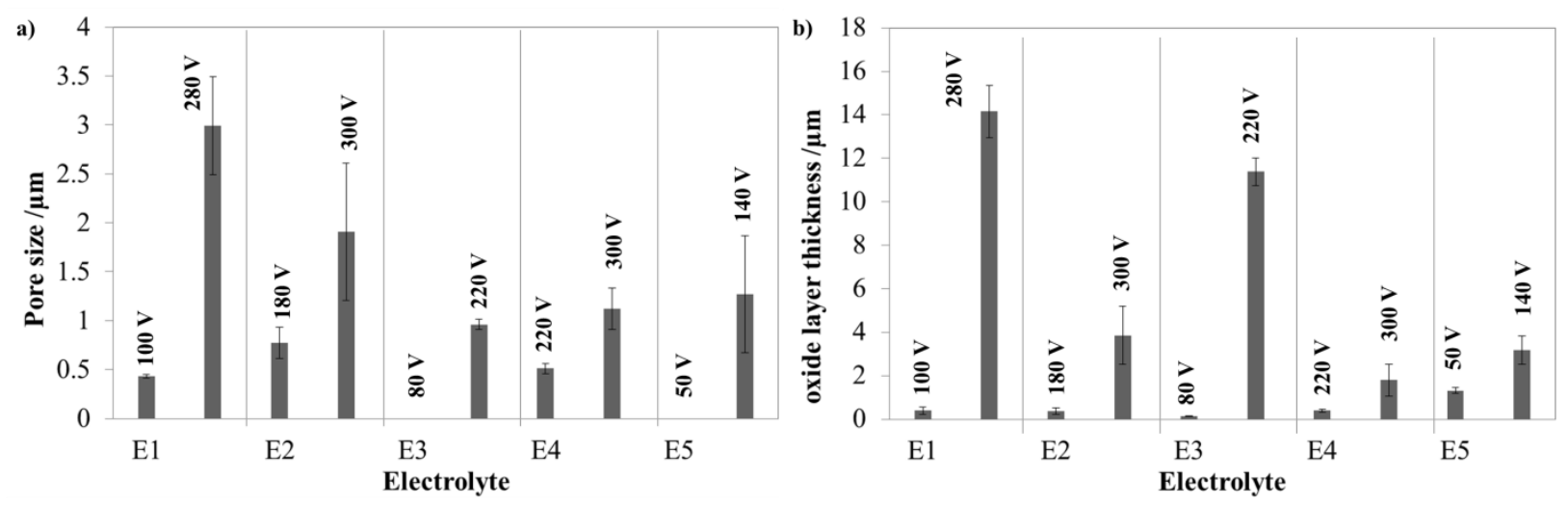

Fig. 5: Pore sizes and oxide layer thickness of the PEO surfaces treated in the different composited electrolytes

The pore sizes of the surfaces are given in Tab. 4 and Fig. 5 were analyzed with the image editing FreeWare software ImageJ (National Institutes of Health, USA). Around 20 pores were measured and the mean value was calculated. An increasing pore size and number of pores on the surface with increasing applied voltage can be determined for all electrolytes. The pore size increases proportionally to the applied voltage of the system. This has been also described by Frauchiger et al. [38]. The higher applied voltage which contains a higher current density increases the energy of the breakdowns and the surface becomes rougher. The same behavior also applies to the oxide layer thickness (Tab. 4). Sul et al. [29] describe a linear growth of the layer with regard to the applied voltage according to the following equation ( $\alpha$ : growth constant $\mathrm{nm} / \mathrm{V})$.

$d=\propto \cdot V$

Compared to Sul et al. [29], a lower oxide layer thickness of alkaline electrolytes can be found for E2 and E5, at nearly $3 \mu \mathrm{m}$, in contrast to the acid electrolytes with a thickness of $10-15 \mu \mathrm{m}$. In acidic electrolytes the oxide layer growth rate is higher than the dissolution rate which results in an increasing layer thickness [39]. On the basis of the higher gas evolution on the surface of the anode, alkaline electrolytes have a lower current yield because of the reduction of the surface area and therefore a lower oxide layer growth rate $[40,41]$. An exception to this is represented by the electrolyte E4, where the layer thickness reaches nearly $1.79 \mu \mathrm{m} \pm 0.72 \mu \mathrm{m}$ in contrast to the other acidic electrolytes with higher thickness of $10-15 \mu \mathrm{m}$. Also in contrast to the other acidic electrolytes, phosphoric acid has a lower current density during the PEO process as seen in Fig. 2. This can result in a lower layer thickness. 


\subsection{XRD-analysis}

To investigate the crystallinity of the PEO surfaces, the anodized samples were examined using X-ray diffraction. The XRD-patterns of the PEO layers were refined for all samples treated with the different electrolytes E1 - E5 (Tab. 2) and are shown in Fig. 6. The applied voltages have a strong influence on the crystallinity of the surfaces. With higher applied voltage the reflection intensity of the titanium substrate decreases whereas the reflections of the crystalline titanium dioxide phases anatase and rutile appear. This indicates an increase in crystallinity, as seen by the dominant anatase reflection at $25^{\circ} 2 \theta\left(\begin{array}{lll}1 & 0 & 1\end{array}\right)$ of the sample treated in E1 at $280 \mathrm{~V}$ and E2 at $320 \mathrm{~V}$. Similarly, the rutile reflection at $27^{\circ} 2 \theta\left(\begin{array}{lll}1 & 1 & 0\end{array}\right)$ increases with higher voltages for electrolytes E1, E3 and E5. Both crystalline phases can be seen in the pattern for E1 at $280 \mathrm{~V}$, which can be an indication of photocatalytic activity. A lower crystallinity at lower voltages for the anodically produced $\mathrm{TiO}_{2}$ surfaces can be detected. The linear increase in crystallinity with respect to the applied voltage was previously reported $[18,32,42,43]$. The crystallinity can be set in context with the reported [44] energy input and the resulting local rise in temperature of the intensified discharges during the increasing voltage.

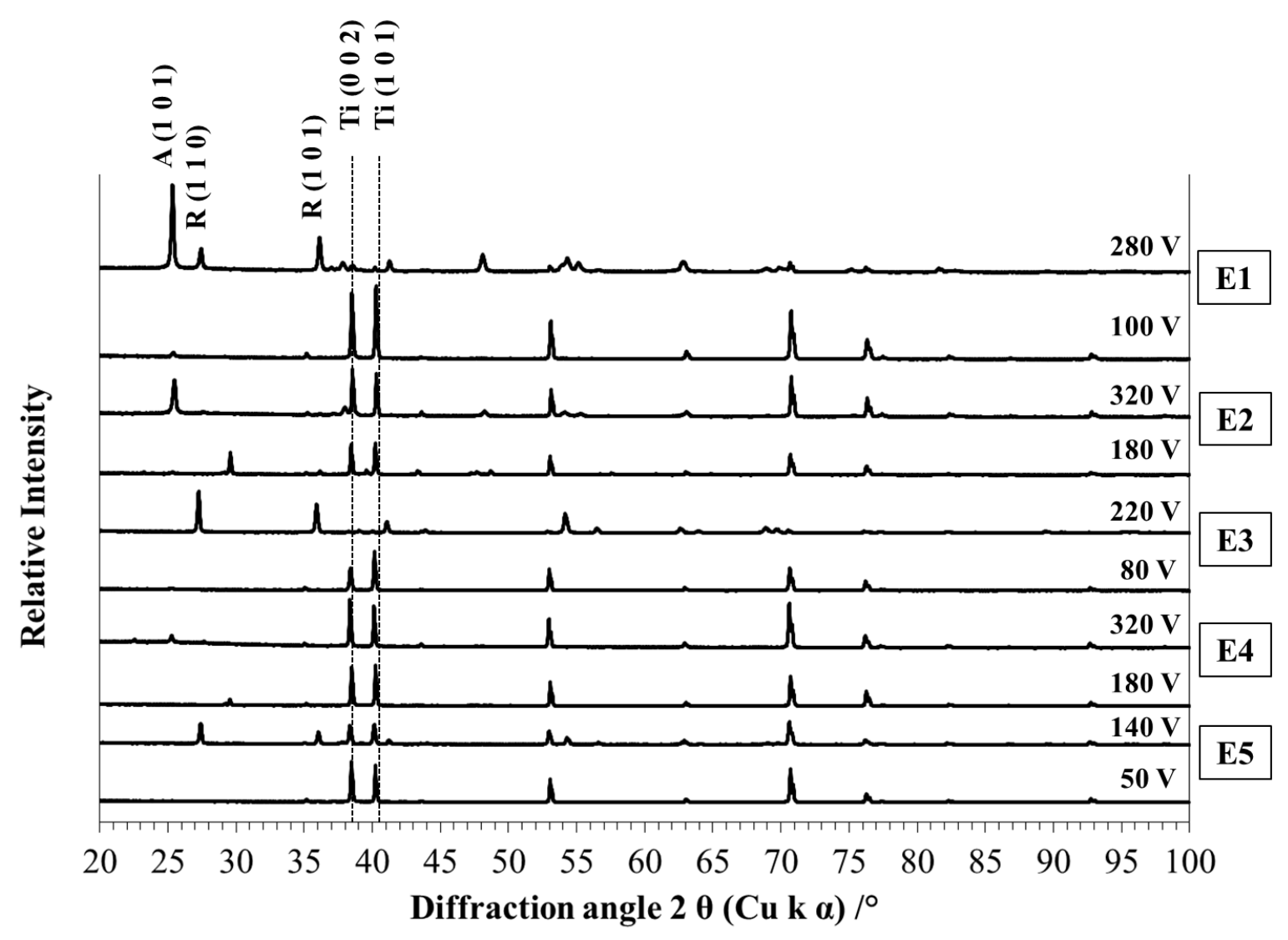

Fig. 6: XRD-patterns of PEO layers produced in the different electrolytes with the highest and the lowest applied voltage (important reflection peaks are marked; A: Anatase, R: Rutile and Ti: Titanium) 
Furthermore, the composition and the conductivity of the electrolyte help to increase the crystallinity of the observed $\mathrm{TiO}_{2}$ phases on the surfaces [32]. Fig. 7 clarifies the percentage of the existing phases on the surfaces. The alkaline electrolyte E2 and the acidic electrolyte E4 both have a low oxidizing nature and produce an anatase-covered surface without any rutile. The second alkaline electrolyte E5, with a higher conductivity than E2, produces in regions of lower voltage mainly anatase on the surface whereas above $115 \mathrm{~V}$ rutile was formed in a higher amounts. The pure sulfuric acid in electrolyte E3 also forms a high amount of rutile on the surfaces with high applied voltages. A mixture of sulfuric acid and phosphoric acid, however, produces a mainly anatase covered surface with a lower proportion of rutile despite its higher conductivity. The more conductive and oxidizing electrolytes E1, E3 and E5 generate a mainly crystalline surface with a higher amount of anatase and rutile. In comparison, E3 and E5 exhibit a high amount of rutile on the surface with higher applied voltage. With increasing voltage, the oxide layer thickness also increases, (see Fig. 5). This leads to the intensity regression of the titanium main reflection peaks. With increasing layer thickness, the pure titanium substrate will be fully covered with $\mathrm{TiO}_{2}$ and the $\mathrm{X}$-ray beam is mainly absorbed by the oxide layer. Because of this, the detection of the titanium substrate is increasingly suppressed. Therefore, primarily the oxide could be detected. With increasing voltage the oxides cover the surface and represent the primarily detected part, leading to a decreasing observability of the metallic titanium. This decreasing titanium amount indicates a growing layer thickness on the surfaces comparable to the SEM micrographs in Fig. 4.
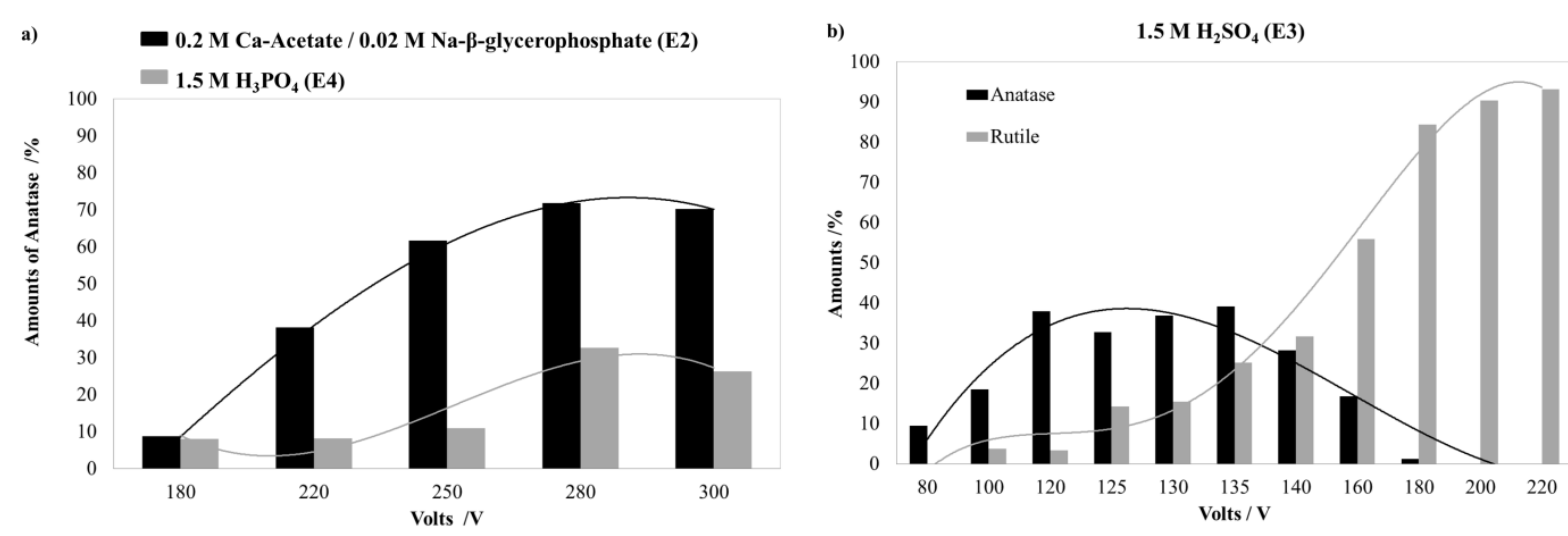

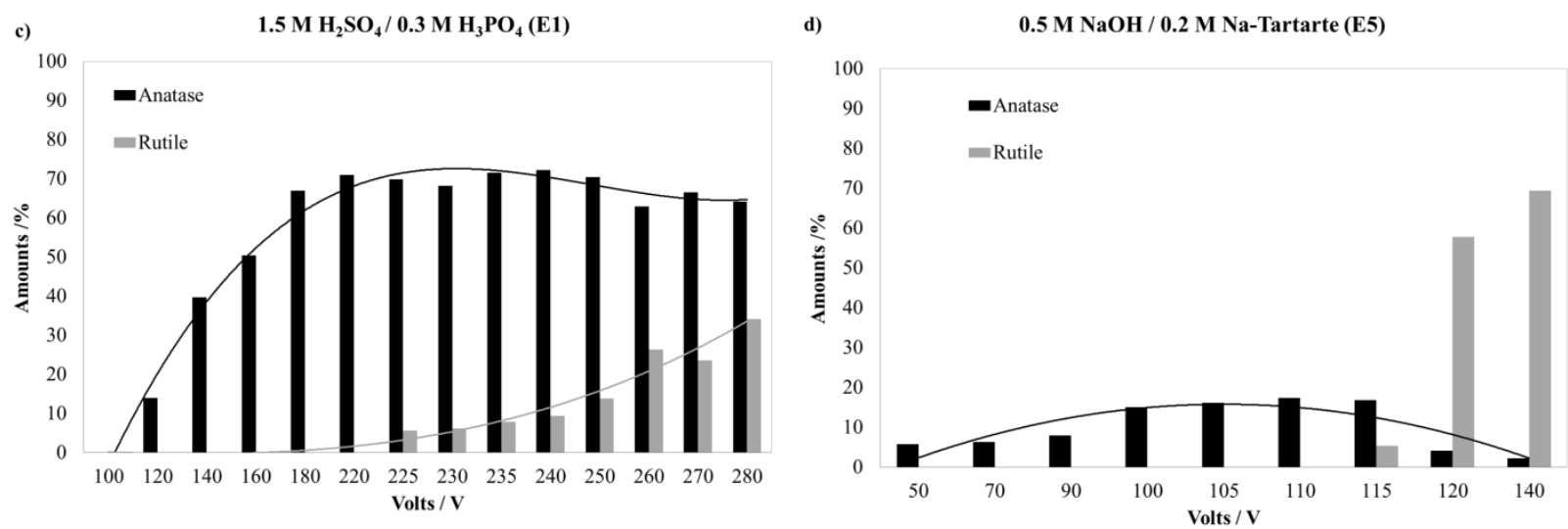

Fig. 7: Amounts in \% of anatase and rutile on the treated PEO surfaces for different voltages (remaining share up to $100 \%$ is titanium substrate)

The increase in crystallinity on the PEO surfaces may affect the lattice parameters of anatase and rutile. The observed lattice parameters for anatase and rutile are plotted in Fig.8. For the lattice parameter $\boldsymbol{a}$ and $\boldsymbol{c}$ of anatase, no significant change can be seen for all used electrolytes. In contrast to anatase the lattice parameters $\boldsymbol{a}$ and $\boldsymbol{c}$ of rutile change exponentially. A marginal change in the lattice parameters of rutile occur between the different electrolytes. The rutile lattice parameter $\boldsymbol{a}$ of E1 increases whereas $\boldsymbol{c}$ decreases compared to those of E3 and E5. The parameter changes in the upper voltage range, in contrast to the other electrolytes where the energy input into the system gets higher. For anatase a lattice expansion at small crystallite sizes is reported [45-48]. For rutile phases Kuznetsov et al. [49] also reported a lattice expansion with decreasing crystallite size, which lead to an anisotropic size-dependent variation of the unit-cell. For electrolyte E1 we found small crystallite sizes between 20 and $30 \mathrm{~nm}$ as shown in Tab. 5. These small crystallite sizes solely for electrolyte E1 suggest that rutile phases on the PEO surfaces are subject to lattice expansion. 

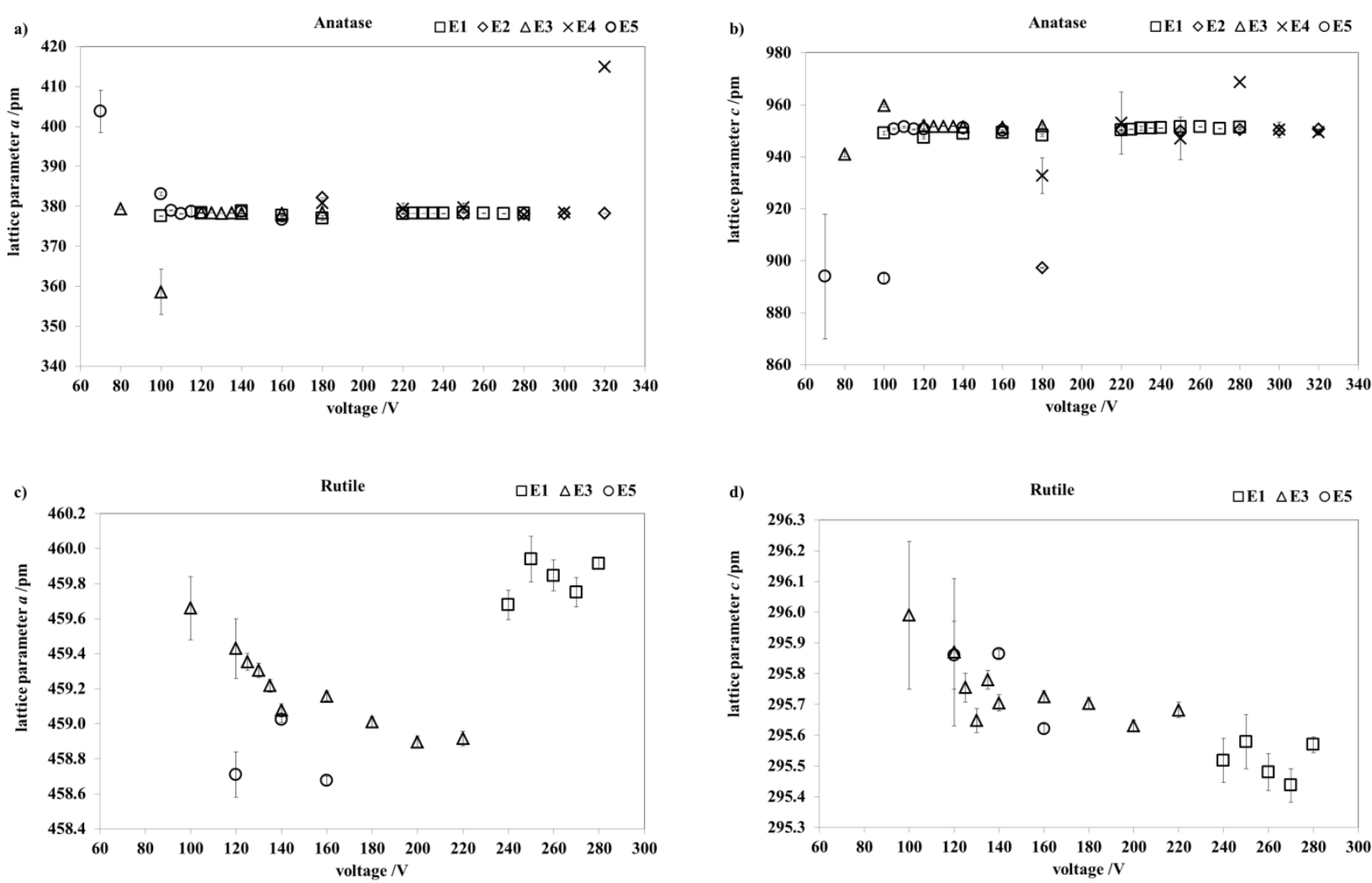

Fig. 8: Lattice parameter of anatase and rutile on the PEO surfaces of the different electrolytes

Tab. 5: Average crystallite sizes $\left(\mathrm{L}_{\mathrm{Vol}}(\mathrm{IB})\right)$ of rutlie for the used electrolytes

\begin{tabular}{lll}
\hline Electrolyte & Applied voltage /V & Middle crystallite size /nm \\
\hline E1 & $230-280$ & $21-38$ \\
E2 & $180-320$ & No rutile \\
E3 & $80-220$ & $35-62$ \\
E4 & $180-320$ & No rutile \\
E5 & $50-160$ & $45-70$ \\
\hline
\end{tabular}

For both crystalline $\mathrm{TiO}_{2}$ polymorphs (anatase and rutile) and the titanium bulk material a preferred orientation of the crystallites can be seen. For titanium a preferred

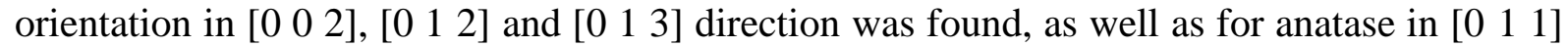

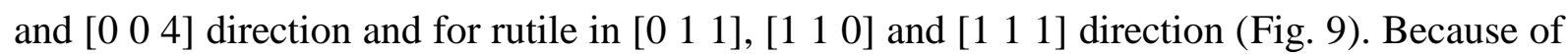
the complex behavior the preferred orientations spherical harmonics were used for the refinement. All titanium samples were cut from the same plate, therefore the preferred orientation of titanium is related to the manufacturing process of the whole plate. The preferred orientation observed for anatase and rutile increases the intensity of the corresponding reflections. Both phases show a preferred orientation of the crystallites in $\left[\begin{array}{lll}0 & 1 & 1\end{array}\right]$ direction. Anatase has a frequent crystal surface [ $\left[\begin{array}{lll}0 & 0 & 1\end{array}\right]$ direction, which leads to a 


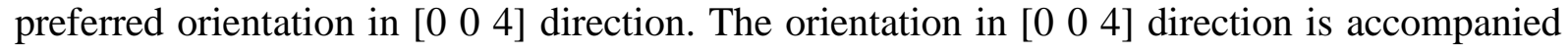
by the general extinction conditions of space group $14_{1} / \mathrm{amd}$. This orientation is related to the preferred orientation direction [0 [ 0 2 $]$ ] of titanium. The anatase preferred orientation in $\left[\begin{array}{lll}0 & 1 & 1\end{array}\right]$ direction is due to the preferred orientation of titanium in [ [ $\left.\begin{array}{lll}0 & 1 & 2\end{array}\right]$ and $\left[\begin{array}{lll}0 & 1 & 3\end{array}\right]$ direction. The same effect can be seen for the preferred orientation direction [ $\left[\begin{array}{lll}0 & 1 & 1\end{array}\right]$ of rutile. The second preferred orientation of rutile in the [lll 110$]$ direction is one of the frequent crystal surface. The PEO-process for pure titanium and its alloys is already characterized in correlation to layer thickness and pore sizes [16,50,51]. Depending on the electrolyte the PEO-process can controll the surface topography as well as the crystallinity of the surface. Therefore, it is possible to tune the crystalline $\mathrm{TiO}_{2}$ surface with a plasma electrolytic oxidation within one synthesis step.

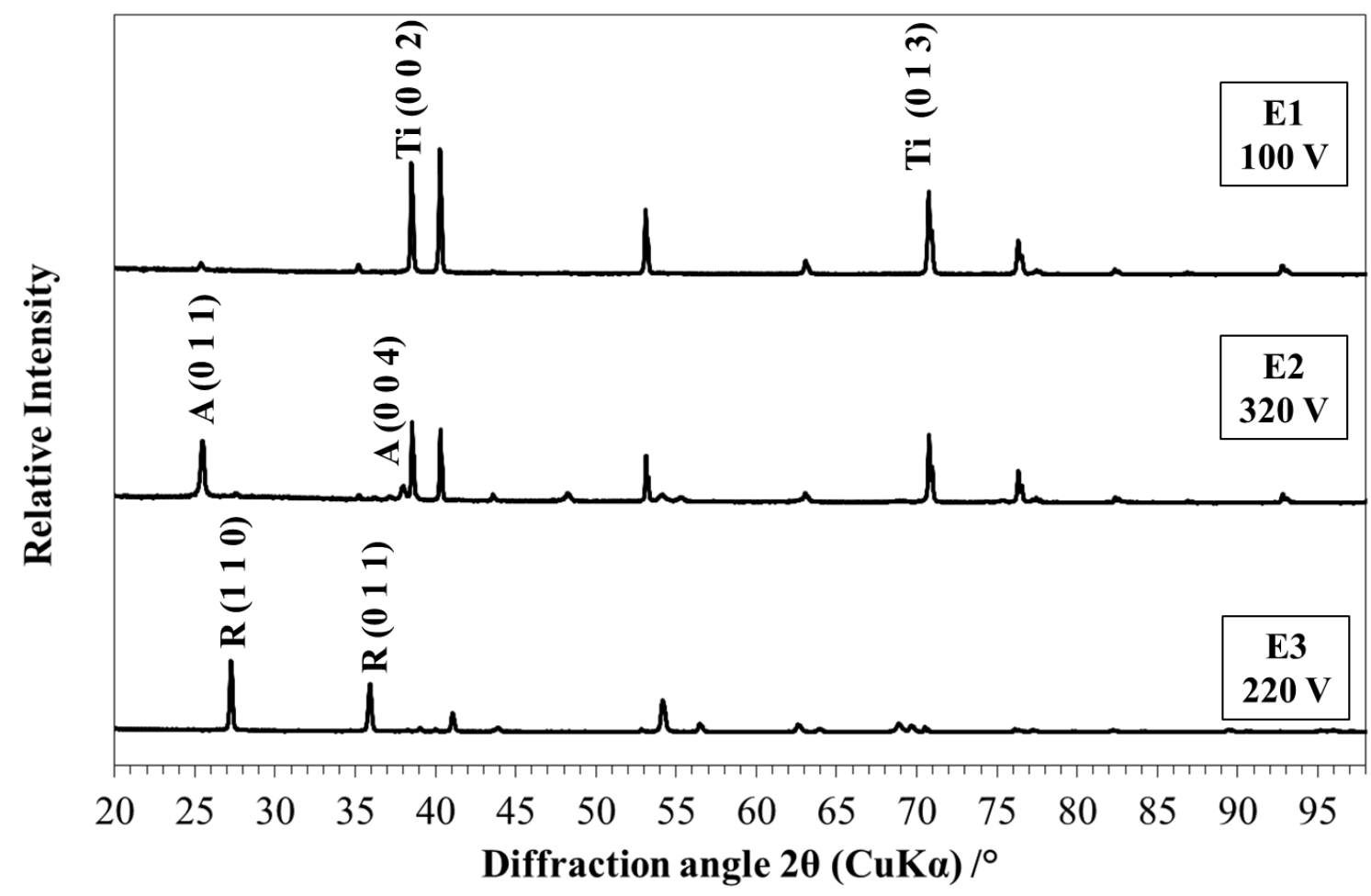

Fig. 9: Preferred orientations of titanium, anatase and rutile on the anodized $\mathrm{TiO}_{2}$ PEO surfaces

\subsection{Photocatalytic activity}

The degradation of methylene blue (MB) dye solution was measured under UV-light irradiation using absorption spectroscopy. The results from the photocatalytic experiments are shown in Fig. 10. For these measurements crystalline PEO surfaces of two electrolytes with an anatase to rutile ratio of approximately $3: 1$ were chosen. This ratio was derived from the photocatalytic active AEROXIDE® $\mathrm{TiO}_{2}$ P 25 (Evonik Resource Efficiency GmbH, Essen, 
Germany, anatase $75 \%$, rutile $25 \%$ ). The amounts on the surfaces of the crystalline dioxides were determined for electrolyte E3 as 67\% anatase and 33\% rutile and for E5 as 75\% anatase and $25 \%$ rutile. The corresponding SEM micrographs of the surfaces and the pore sizes as well as the layer thicknesses are shown in Fig. 11 and Tab. 6. For both PEO treated samples, photocatalytic activity can already be seen after one day of irradiation with UV-light. The absorption intensity compared to the initial methylene blue concentration clearly decreases. For the sample prepared in the electrolyte E3 (rutile amount 30\%) a higher decreasing rate of MB concentration against electrolyte E5 (rutile amount 25\%) was observed. This may indicate that a low amount of anatase and a comparable higher amount of rutile with respect to P25 can show better photocatalytic activity for these surfaces, unlike as was reported by Bayati et al. [19]. For comparison one non-illuminated PEO sample in Fig. 10 c) and a pure methylene blue solution under UV-light in Fig.10 d) were investigated. Both samples showed a low degradation rate during the entire experiment, which could be also an absorption effect of the dye on the surfaces, in general, however, an absorption or splitting effect of MB at the porous PEO surfaces can be ruled out.
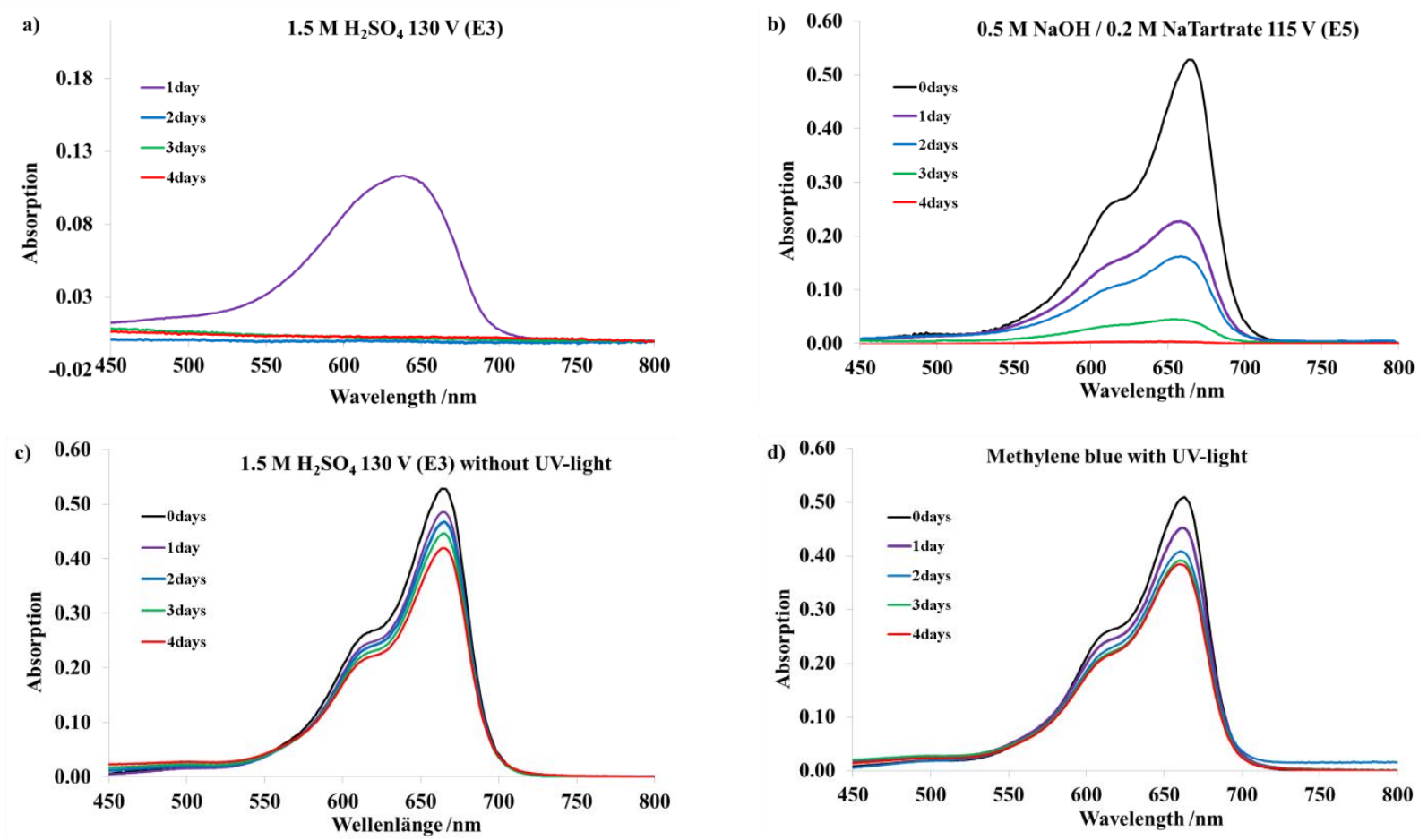

Fig. 10: Degradation of absorption intensity during 4 days of the MB for the rinsed PEO layer with the best Anatase to Rutile ratio and illuminated methylene blue and a pure titanium plate 

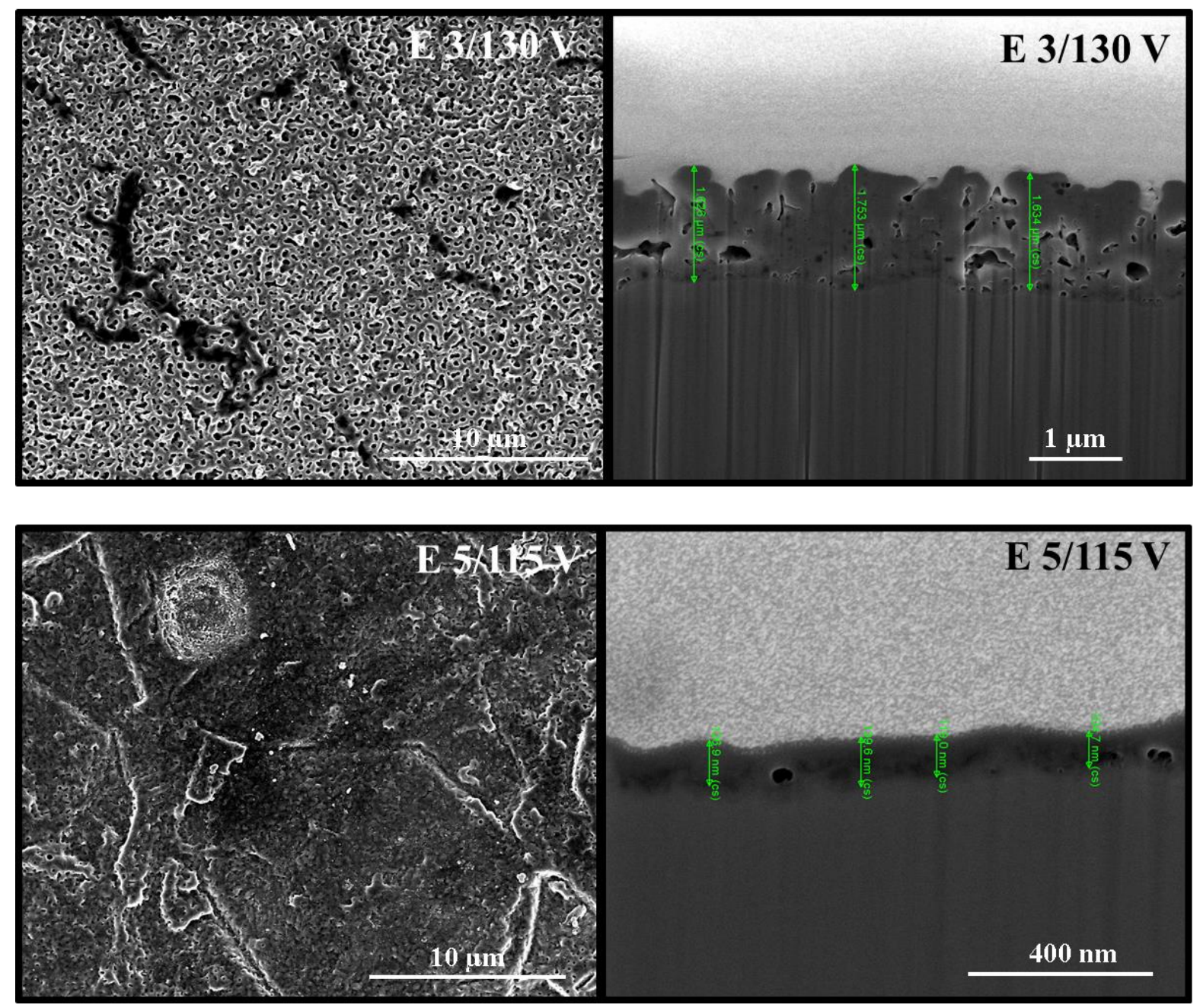

Fig. 11: SEM micrographs showing the surface morphologies and the oxide layer thickness of the PEO treated Ti-plates using in the photocatalytic test

Tab. 6: Pore sizes and oxide layer thickness of the PEO surfaces used for the photocatalytic test

\begin{tabular}{l|l|l}
\hline Electrolyte & $\mathbf{E 3}$ & $\mathbf{E 5}$ \\
\hline Applied voltage/ V & $\mathbf{1 3 0}$ & $\mathbf{1 1 5}$ \\
Pore size/ $\mu \mathrm{m}$ & $0.155 \pm 0.03$ & $0.161 \pm 0.04$ \\
Oxide layer thickness $/ \mu \mathrm{m}$ & $1.67 \pm 0.07$ & $0.144 \pm 0.03$ \\
\hline
\end{tabular}

The photocatalytic activity can be controlled with the nature of the electrolytes and the associated crystallinity of the PEO surfaces. The samples treated in E3 show the best degradation rate after the entire irradiation period. Against the optimal ratio of anatase and rutile from 3:1 this sample shows a ratio of 2:1 (130 V). For MB there is an ongoing discussion regarding the adsorption and splitting effects at surfaces. Thus it can be assumed that there is photocatalytic activity after the illumination for both PEO surfaces. 


\section{Conclusion}

The impact of the variation of the electrolytic system for the plasma electrolytic oxidation (PEO) on the electrochemical, morphological, crystallographic and photocatalytic properties of the titania layers were investigated. It was possible to synthesize titania layers with an individual morphology and a high crystallization level. The tuned PEO process allows an adjustment of the pore sizes and oxide layers of the titania surfaces in any desired direction. A higher breakdown voltage could be found for alkaline solutions, in contrast to acidic solutions, because of the lower conductivity and a strong gas evolution, which reduces the anode area for oxidation. This also affects the layer thicknesses, which are less in comparison to the acidic electrolytes. With phosphate $\left(\mathrm{PO}_{4}{ }^{2-}\right)$-containing electrolytes, the pores can take on a round shape compared to the electrolyte containing hydroxide anions $\left(\mathrm{OH}^{-}\right)$, where the pores become more linear. A new type of appearance of the pores in sulfuric acid $\left(\mathrm{H}_{2} \mathrm{SO}_{4}\right)$, with stacked cavity-containing layers could be developed. Therefore, by varying the composition of the electrolyte, the appearance of the pores can be changed and formed for specifical applications. The applied voltages and the composition of the electrolytes successfully produce a high crystallinity of the oxide layer with mainly anatase and rutile phases. For titanium, anatase and rutile, there can be found a preferred orientation of the crystallites on the surfaces. At this point a preferred direction of growth in [ $\left[\begin{array}{lll}0 & \mathrm{k} & 1\end{array}\right]$ and $\left[\begin{array}{lll}0 & 0 & 1\end{array}\right]$ can be concluded. The ratio of the crystalline phases anatase and rutile could be optimized in contrast to P25 because these high crystalline $\mathrm{TiO}_{2}$ coatings show photocatalytic activity. From the results of the photocatalytic behavior the samples prepared in $1.5 \mathrm{M} \mathrm{H}_{2} \mathrm{SO}_{4}$ show the highest activity with a ratio of anatase to rutile of $2: 1$. These samples have an optimal crystallite size of between 30 and $40 \mathrm{~nm}$, which positively affected the activity.

\section{Acknowledgement}

The authors want to thank Dr. Karsten Thiel for his assistance with the SEM measurements and the creation of the SEM micrographs of the prepared surfaces.

This research did not receive any specific grant from funding agencies in the public, commercial, or not-for-profit sectors. 


\section{References}

[1] M. Nganbe, H. Louati, U. Khan, A. Speirs, P.E. Beaulé, Retrieval analysis and in vitro assessment of strength, durability, and distraction of a modular total hip replacement, J. Biomed. Mater. Res. - Part A. 95 (2010) 819-827. doi:10.1002/jbm.a.32886.

[2] R.C. Petersen, Titanium Implant Osseointegration Problems with Alternate Solutions Using Epoxy/Carbon-Fiber-Reinforced Composite, Metals (Basel). 4 (2014) 549-569. doi:10.3390/met4040549.

[3] S. Sreekantan, K.A. Saharudin, L.C. Wei, Nanotubes Via Anodization and Potential Applications for Photocatalysts, Biomedical Materials, and Photoelectrochemical Cell, IOP Conf. Ser. Mater. Sci. Eng. 21 (2011) 12002. doi:10.1088/1757$899 X / 21 / 1 / 012002$.

[4] P. Roy, S. Berger, P. Schmuki, TiO2-Nanoröhren: Synthese und Anwendungen, Angew. Chemie. 123 (2011) 2956-2995. doi:10.1002/ange.201001374.

[5] N.P. Sluginov, -, J. Russ. Phys. Chem. 12 (1880) 1-2.

[6] A.G. Schulze, H. Betz, Electrolytkondensatoren-Ihre Entwicklung, wissenschaftliche Grundlage, Herstellung, Messung und Verwendung, Krayn. (1937).

[7] N.G. Mc Niell W., Method of making cadmium niobate, US2854390 A, 1958.

[8] Mc Niell W.; Nordbloom G., Anodic spark reaction processes and articles, US 3293158 A, 1966.

[9] M.G. Markov G., The formation method of anodic electrolytic condensation, 526961, 1976.

[10] B.I. Nikolaev, A.V.; Markov, G.A.; Peshchevitskij, No Title, Izv. SO ANSSSR. Ser. Khim. Nauk 5. 5 (1977) 32.

[11] S. Stojadinović, R. Vasilić, M. Petković, B. Kasalica, I. Belča, A. Žekić, L. Zeković, Characterization of the plasma electrolytic oxidation of titanium in sodium metasilicate, Appl. Surf. Sci. 265 (2013) 226-233. doi:10.1016/j.apsusc.2012.10.183.

[12] X. Liu, P.K. Chu, C. Ding, Surface nano-functionalization of biomaterials, Mater. Sci. Eng. R Reports. 70 (2010) 275-302. doi:10.1016/j.mser.2010.06.013. 
[13] D. Quintero, O. Galvis, J.A. Calderón, J.G. Castaño, F. Echeverría, Effect of electrochemical parameters on the formation of anodic films on commercially pure titanium by plasma electrolytic oxidation, Surf. Coatings Technol. 258 (2014) 12231231. doi:10.1016/j.surfcoat.2014.06.058.

[14] T. Akatsu, Y. Yamada, Y. Hoshikawa, T. Onoki, Y. Shinoda, F. Wakai, Multifunctional porous titanium oxide coating with apatite forming ability and photocatalytic activity on a titanium substrate formed by plasma electrolytic oxidation, Mater. Sci. Eng. C. 33 (2013) 4871-4875. doi:10.1016/j.msec.2013.08.003.

[15] S. Uttiya, D. Contarino, S. Prandi, M. Carnasciali, G. Gemme, L. Mattera, R. Rolandi, Anodic Oxidation of Titanium in Sulphuric Acid and Phosphoric Acid Electrolytes, J. Mater. .... 1 (2009) 2. doi:10.15744/2348-9812.1.S106.

[16] H.J. Oh, J.H. Lee, Y. Jeong, Y.J. Kim, C.S. Chi, Microstructural characterization of biomedical titanium oxide film fabricated by electrochemical method, Surf. Coatings Technol. 198 (2005) 247-252. doi:10.1016/j.surfcoat.2004.10.029.

[17] Y. Mizukoshi, N. Masahashi, Fabrication of a TiO2 photocatalyst by anodic oxidation of Ti in an acetic acid electrolyte, Surf. Coatings Technol. 240 (2014) 226-232. doi:10.1016/j.surfcoat.2013.12.030.

[18] M.R. Bayati, F. Golestani-Fard, A.Z. Moshfegh, The effect of growth parameters on photo-catalytic performance of the MAO-synthesized TiO2 nano-porous layers, Mater. Chem. Phys. 120 (2010) 582-589. doi:10.1016/j.matchemphys.2009.12.005.

[19] M.R. Bayati, F. Golestani-Fard, A.Z. Moshfegh, How photocatalytic activity of the MAO-grown $\mathrm{TiO} 2$ nano/micro-porous films is influenced by growth parameters?, Appl. Surf. Sci. 256 (2010) 4253-4259. doi:10.1016/j.apsusc.2010.02.011.

[20] L.K. Mirelman, J.A. Curran, T.W. Clyne, The production of anatase-rich photoactive coatings by plasma electrolytic oxidation, Surf. Coatings Technol. 207 (2012) 66-71. doi:10.1016/j.surfcoat.2012.05.076.

[21] M.L. Kääriäinen, T.O. Kääriäinen, D.C. Cameron, Titanium dioxide thin films, their structure and its effect on their photoactivity and photocatalytic properties, Thin Solid Films. 517 (2009) 6666-6670. doi:10.1016/j.tsf.2009.05.001.

[22] S.K. Poznyak, D. V. Talapin, A.I. Kulak, Electrochemical oxidation of titanium by 
pulsed discharge in electrolyte, J. Electroanal. Chem. 579 (2005) 299-310. doi:10.1016/j.jelechem.2005.03.002.

[23] J. He, Q.Z. Cai, Y.G. Ji, H.H. Luo, D.J. Li, B. Yu, Influence of fluorine on the structure and photocatalytic activity of $\mathrm{TiO} 2$ film prepared in tungstate-electrolyte via micro-arc oxidation, J. Alloys Compd. 482 (2009) 476-481. doi:10.1016/j.jallcom.2009.04.063.

[24] J.F. Li, L. Wan, J.Y. Feng, Study on the preparation of titania films for photocatalytic application by micro-arc oxidation, Sol. Energy Mater. Sol. Cells. 90 (2006) 24492455. doi:10.1016/j.solmat.2006.03.017.

[25] Y. Han, S.-H. Hong, K. Xu, Synthesis of nanocrystalline titania films by micro-arc oxidation, Mater. Lett. 56 (2002) 744-747. doi:10.1016/S0167-577X(02)00606-7.

[26] R. H. U. Khan; A. L. Yerokhin; A. Metthews, Structural characteristics and residual stresses in oxide films produced on Ti by pulsed unipolar plasma electrolytic oxidation, Philos. Mag. 88 (2008) 795. doi:http://dx.doi.org/10.1080/14786430801968603.

[27] K. Venkateswarlu, N. Rameshbabu, D. Sreekanth, M. Sandhyarani, A.C. Bose, V. Muthupandi, S. Subramanian, Role of electrolyte chemistry on electronic and in vitro electrochemical properties of micro-arc oxidized titania films on $\mathrm{Cp} \mathrm{Ti}$, Electrochim. Acta. 105 (2013) 468-480. doi:10.1016/j.electacta.2013.05.032.

[28] S. Ikonopisov, Theory of electrical breakdown during formation of barrier anodic films, Electrochim. Acta. 22 (1977) 1077-1082. doi:10.1016/0013-4686(77)80042-X.

[29] Y.T. Sul, C.B. Johansson, Y. Jeong, T. Albrektsson, The electrochemical oxide growth behaviour on titanium in acid and alkaline electrolytes, Med. Eng. Phys. 23 (2001) 329-346. doi:10.1016/S1350-4533(01)00050-9.

[30] O.Z. P. Kern, Purified titanium oxide with novel morphologies upon spark anodization of Ti alloys in mixed H2SO4/H3PO4 electrolytes, J. Biomed. Mater. Res. Part A. 80A (2006) 283-296. doi:10.1002/jbm.a.

[31] A.L. Yerokhin, X. Nie, A. Leyland, A. Matthews, S.J. Dowey, Plasma electrolysis for surface engineering, Surf. Coatings Technol. 122 (1999) 73-93. doi:10.1016/S02578972(99)00441-7.

[32] Z. Su, L. Zhang, F. Jiang, M. Hong, Formation of crystalline TiO2 by anodic oxidation of titanium, Prog. Nat. Sci. Mater. Int. 23 (2013) 294-301. 
doi:10.1016/j.pnsc.2013.04.004.

[33] M. Schmidt, J.; Schrader, C.; Tzschach, Die plasmachemische Oxidation von Leichtmetallen für optische und medizinische Anwendungen, Galvanotechnik. (2012) $2416-2427$.

[34] H. Ishizawa, M. Ogino, Formation and characterization of anodic titanium oxide films containing $\mathrm{Ca}$ and P, J. Biomed. Mater. Res. 29 (1995) 65-72. doi:10.1002/jbm.820290110.

[35] S. ITO, K. KOIZUKA, M. HIROCHI, T. ONAKA, H.M.T. HANEDA, Anodic Oxidation of Titanium in Phosphoric Acid-Sulfuric Acid System Electrolytic Bath, J. Japan Soc. Colour Mater. 61 (1988) 599-605.

[36] Y.K. Shin, W.S. Chae, Y.W. Song, Y.M. Sung, Formation of titania photocatalyst films by microarc oxidation of Ti and Ti-6Al-4V alloys, Electrochem. Commun. 8 (2006) 465-470. doi:10.1016/j.elecom.2006.01.003.

[37] K.-H. Kim, N. Ramaswamy, Electrochemical surface modification of titanium in dentistry., Dent. Mater. J. 28 (2009) 20-36. doi:10.4012/dmj.28.20.

[38] V.M. Frauchiger, F. Schlottig, B. Gasser, M. Textor, Anodic plasma-chemical treatment of CP titanium surfaces for biomedical applications, Biomaterials. 25 (2004) 593-606. doi:10.1016/S0142-9612(03)00560-X.

[39] M.E. Sibert, Electrochemical oxidation of titanium surfaces, J. Electrochem. Soc. 110 (1963) 65-71.

[40] J.S.L. Dyer, K C; Leach, Breakdown and efficiency of anodic oxide growth on titanium, J. Electrochem. Soc. 125 (1978) 1032-1038.

[41] N. Ohtsuka, T; Masuda, M; Sato, Ellipsometric study of anodic oxide films on titanium in hydrochloric acid, sulfuric acid, and phosphate solution, J. Electrochem. Soc. 132 (1985) 787-92.

[42] Y. Mizukoshi, N. Masahashi, Photocatalytic Activities and Crystal Structures of Titanium Dioxide by Anodization: Their Dependence upon Current Density, Mater. Trans. 51 (2010) 1443-1448. doi:10.2320/matertrans.M2010106.

[43] M. V. Diamanti, M.P. Pedeferri, Effect of anodic oxidation parameters on the titanium 
oxides formation, Corros. Sci. 49 (2007) 939-948. doi:10.1016/j.corsci.2006.04.002.

[44] C.S. Dunleavy, J.A. Curran, T.W. Clyne, Self-similar scaling of discharge events through PEO coatings on aluminium, Surf. Coatings Technol. 206 (2011) 1051-1061. doi:10.1016/j.surfcoat.2011.07.065.

[45] V. Swamy, D. Menzies, B.C. Muddle, A. Kuznetsov, L.S. Dubrovinsky, Q. Dai, V. Dmitriev, Nonlinear size dependence of anatase TiO2 lattice parameters, Appl. Phys. Lett. 88 (2006) 1-4. doi:10.1063/1.2213956.

[46] I. Djerdj, A.M. Tonejc, Structural investigations of nanocrystalline TiO2 samples, J. Alloys Compd. 413 (2006) 159-174. doi:10.1016/j.jallcom.2005.02.105.

[47] I.E. Grey, N.C. Wilson, Titanium vacancy defects in sol-gel prepared anatase, J. Solid State Chem. 180 (2007) 670-678. doi:10.1016/j.jssc.2006.11.028.

[48] Y. Li, T.. White, S.. Lim, Low-temperature synthesis and microstructural control of titania nano-particles, J. Solid State Chem. 177 (2004) 1372-1381. doi:10.1016/j.jssc.2003.11.016.

[49] A.Y. Kuznetsov, R. MacHado, L.S. Gomes, C.A. Achete, V. Swamy, B.C. Muddle, V. Prakapenka, Size dependence of rutile $\mathrm{TiO} 2$ lattice parameters determined via simultaneous size, strain, and shape modeling, Appl. Phys. Lett. 94 (2009) 2009-2011. doi:10.1063/1.3139078.

[50] N.K. Kuromoto, R.A. Simão, G.A. Soares, Titanium oxide films produced on commercially pure titanium by anodic oxidation with different voltages, Mater. Charact. 58 (2007) 114-121. doi:10.1016/j.matchar.2006.03.020.

[51] H. Te Chen, C.H. Hsiao, H.Y. Long, C.J. Chung, C.H. Tang, K.C. Chen, J.L. He, Micro-arc oxidation of $\beta$-titanium alloy: Structural characterization and osteoblast compatibility, Surf. Coatings Technol. 204 (2009) 1126-1131. doi:10.1016/j.surfcoat.2009.06.043. 